\title{
Effectiveness of omalizumab in an asthmatic patient with severe airway and blood eosinophilia
}

\author{
Izabela Kupryś-Lipińska ${ }^{1}$, Marta Kołacińska-Flont ${ }^{1}$, Jerzy Marczak², Paweł Górski², Zofia Kurmanowska², Piotr Kuna ${ }^{1}$ \\ ${ }^{1}$ Department of Internal Medicine, Asthma and Allergy, Norbert Barlicki Memorial University Hospital No. 1, Medical University of Lodz, \\ Lodz, Poland \\ Head of the Department: Prof. Piotr Kuna MD, PhD \\ ${ }^{2}$ Department of Pneumonology and Allergology, Norbert Barlicki Memorial University Hospital No. 1, Medical University of Lodz, Lodz, \\ Poland \\ Head of the Department: Prof. Paweł Górski MD, PhD
}

Postep Derm Alergol 2015; XXXII (6): 478-479

DOI: $10.5114 /$ pdia.2015.48072

Omalizumab is a monoclonal antibody raised against class E immunoglobulin (lgE), approved for the treatment of chronic severe (in the EU) or moderate-to-severe (in the USA) IgE-mediated asthma. Omalizumab is effective in reducing asthma exacerbations, hospitalizations and emergency visits due to exacerbations as well as in improving patients' quality of life (QoL) [1-3].

Here we report on a 41-year-old man suffering from severe allergic asthma with systemic and airway eosinophilia, despite using high-dose systemic corticosteroids. The disease began at the age of 36 with cough, dyspnea and poor exercise tolerance. The therapy included highdose inhaled corticosteroids (ICS) in combination with long-acting $\beta_{2}$-agonists (LABA), antileukotriene antagonists and rescue short acting $\beta_{2}$-agonists (SABA). From the beginning, the disease has been severe and uncontrolled. Since 2011, dyspnea had been so severe that the patient permanently received $16 \mathrm{mg}$ of methylprednisolone per day. Reduction of this dose ended up with a loss of asthma control. Moreover, the patient underwent functional endoscopic sinus surgery, due to turbinate hypertrophy.

In 2012, the patient was referred to our Department for a thorough diagnostic assessment. A 2-week washout from oral corticosteroids (OCS) was performed. On admission, the patient complained of significant breathlessness, wheezing, persistent productive cough and substantial limitation of exercise capacity. Physical examination revealed soft vesicular sound with a prolonged expiratory phase, numerous wheezes and rhonchi. Spirometry showed severe airflow limitation $\left(\mathrm{FEV}_{1}=\right.$ 1.47 I (36\% of a normal value $(N)), F V C=4.15$ । $(88 \% N)$, FEV1\%FVC $=35.42 \%)$; reversibility test with bronchodilator was negative. Skin prick tests were positive for house dust mites and Alternaria sp. A class 2 specific IgE level was determined for Alternaria sp. by ELISA.

The blood eosinophil count was significantly increased ( $E O=1.7 \times 10^{3} / \mu \mathrm{l}-15.9 \%$ of white blood cells). Bronchoscopy revealed thick secretions covering bronchi and a very high airway eosinophilia ( $E O=56.2 \%$ ), as measured in bronchoalveolar lavage. Additional tests excluded parasites and protozoans infection as well as hypereosinophilic syndrome.

The final diagnosis at discharge was persistent severe asthma associated with chronic rhinosinusitis.

The patient was deemed to qualify for omalizumab treatment but due to reimbursement problems he could start this therapy only in April 2013, when the program of treatment of severe IgE-dependent asthma with omalizumab began (funded by the National Health Fund - NFZ). Until that time, despite persistent OCS therapy (16 mg methylprednisolone/day), blood eosinophil count remained high $\left(\mathrm{EO}=0.58 \times 10^{3} / \mu \mathrm{l}-6.5 \%\right)$.

The calculated dose of omalizumab, based on patient's IgE level (306 kU/l) and weight (88 kg), was $600 \mathrm{mg}$ every 4 weeks. After 16 weeks of therapy, asthma control significantly improved (Asthma Control Questionnaire - ACQ) decreased from 3.7 to 2.5 points. The daily dose of OCS could be reduced (from 16 to $4 \mathrm{mg}$ methylprednisolone/day) without asthma exacerbations. Lung function and patient's QoL improved (FEV from 44\% to 60\% N; Asthma Quality-of-Life Questionnaire (AQLQ) from 3.2 to 4.3 points). Moreover, the peripheral blood eosinophil count normalized ( $\mathrm{EO}=0.08 \times 10^{3} / \mu \mathrm{l}-1.1 \%$ ), despite a significant decrease in OCS dose. The effectiveness in the Global Effectiveness Treatment Evaluation (GETE) scale was assessed as good.

Address for correspondence: Izabela Kupryś-Lipińska MD, PhD, Department of Internal Medicine, Asthma and Allergy, Norbert Barlicki Memorial University Hospital No. 1, Medical University of Lodz, 22 Kopcinskiego St, 90-153 Lodz, Poland, phone: +48 606819702, fax: +48 42678 11 76, e-mail: ikuprys@wp.pl Received: 10.03 .2014 , accepted: 10.12 .2014$. 
Omalizumab acts by blocking free circulating IgE and inhibiting their binding to IgE high-affinity receptors. Additionally, omalizumab down-regulates IgE receptor expression on effector cells. This way, omalizumab inhibits mast cell and basophil degranulation and the consequent release of inflammatory mediators. However, its role within the context of allergic inflammation is perhaps much more complex [2].

Airway eosinophilic inflammation is a characteristic feature of asthma and can be associated with a mild peripheral blood eosinophilia [4]. The number of sputum eosinophils closely correlates with asthma severity [5] as well as with a risk and severity of exacerbations. Furthermore, assessment of anti-inflammatory treatment in asthma, based on the eosinophil count in sputum, is more efficient than assessment based on symptoms and lung function $[6,7]$. Eosinophils are extremely sensitive to corticosteroids but there is a subpopulation of asthmatics who are resistant to OCS, even at a high dose. Endobronchial biopsies and bronchoalveolar lavage performed in patients with steroid-resistant asthma show a high eosinophil number despite therapy with OCS [8].

In our patient both severe airway eosinophilia and systemic eosinophilia appeared to be related to severe asthma. Sixteen weeks of omalizumab treatment not only improved asthma control and prevented exacerbation but also allowed a four-fold reduction in OCS daily dose and normalized blood eosinophils.

New data are showing the effectiveness of omalizumab in asthmatic patients with blood eosinophilia, as observed also by us in another patient with severe asthma and chronic urticaria [9]. A similar effect was observed in 5 patients with asthma and severe peripheral blood eosinophilia. After 16 weeks of OMA, the eosinophil count decreased to nearly normal levels, simultaneously with a reduction in OCS daily dose and the number of monthly exacerbations [10].

In Massanari's pooled analysis of five clinical studies on the effectiveness of omalizumab in patients with moderate-to-severe persistent allergic asthma, post-treatment eosinophil count in peripheral blood compared to baseline was reduced in the omalizumab group only. Investigators found that a decrease in peripheral blood eosinophils was parallel to the improvement in various clinical outcomes (severe exacerbations, FEV $_{1}$, GETE) [11]. In another study, a significant (56\%) reduction in severe asthma exacerbations by omalizumab, as compared to placebo, was achieved only in the high eosinophil group ( $\geq 260 \mathrm{EO} / \mu \mathrm{l})$ [12].

Yet another study assessed the effect of omalizumab on airway eosinophilia in 45 patients with mild-to-moderate asthma and sputum eosinophilia (EO $\geq 2 \%$ ). After 16 weeks of treatment, the number of eosinophils in induced sputum and in bronchial tissues (obtained by bronchial biopsies) were significantly reduced (although airway hyperresponsiveness to methacholine did not improve) [13].
The effect of omalizumab on eosinophils, besides neutralization of IgE, seems to be another important mechanism of its action in asthma. Patients with severe refractory asthma and airway and systemic eosinophilia seem to be good candidates for treatment with this drug. Eosinophils, on the other hand, could be a potential biomarker for prediction of the omalizumab treatment outcome.

\section{Conflict of interest}

Izabela Kupryś-Lipińska and Piotr Kuna declare honoraria from Novartis for lectures.

Marta Kołacińska-Flont, Jerzy Marczak, Paweł Górski and Zofia Kurmanowska declare no conflict of interest.

\section{References}

1. Kuprys-Lipinska I, Kuna P. Loss of asthma control after cessation of omalizumab treatment - real life data. Postep Derm Alergol 2014; 31: 1-5.

2. Kupczyk M, Kuna P. Omalizumab in an allergology clinic: real life experience and future developments. Postep Derm Alergol 2014; 31: 32-5.

3. Jerzyńska J, Sztafińska A, Woicka-Kolejwa K, Stelmach I. Omalizumab as a new therapeutic approach for children with severe asthma. Postep Derm Alergol 2014; 31: 45-6.

4. Stone KD, Prussin C, Metcalfe DD. IgE, mast cells, basophils, and eosinophils. J Allergy Clin Immunol 2010; 125 (2 Suppl.): S73-80.

5. Louis R, Lau LC, Bron AO, et al. The relationship between airways inflammation and asthma severity. Am J Respir Crit Care Med 2000; 161: 9-16.

6. Green RH, Brightling CE, McKenna S, et al. Asthma exacerbations and sputum eosinophil counts: a randomised controlled trial. Lancet 2002; 360: 1715-21.

7. Petsky HL, Kynaston JA, Turner C, et al. Tailored interventions based on sputum eosinophils versus clinical symptoms for asthma in children and adults (Review). Cochrane Database Syst Rev 2007; 2: CD005603.

8. Leung DYM, Martin RJ, Szefler SJ, et al. Dysregulation of interleukin 4, interleukin 5, and interferon gamma gene expression in steroid-resistant asthma. J Exp Med 1995; 181: 33-40.

9. Kupryś-Lipińska I, Korczyńska P, Tworek D, Kuna P. Effectiveness of omalizumab in a patient with life-threatening episode of bronchospasm and larynx angioedema after exposure to house dust. Postep Derm Alergol 2014; 31: 39-44.

10. Pelaia G, Gallelli L, Romeo P, et al. Omalizumab decreases exacerbation frequency, oral intake of corticosteroids and peripheral blood eosinophils in atopic patients with uncontrolled asthma. Int J Clin Pharmacol Ther 2011; 49: 713-21.

11. Massanari M, Holgate ST, Busse WW, et al. Effect of omalizumab on peripheral blood eosinophilia in allergic asthma. Respir Med 2010; 104: 188-96.

12. Hanania NA, Wenzel S, Rosén K, et al. Exploring the effects of omalizumab in allergic asthma: an analysis of biomarkers in the EXTRA study. Am J Respir Crit Care Med 2013; 187: 804-11.

13. Djukanović R, Wilson SJ, Kraft M, et al. Effects of treatment with anti-immunoglobulin $\mathrm{E}$ antibody omalizumab on airway inflammation in allergic asthma. Am J Respir Crit Care Med 2004; 170: 583-93. 